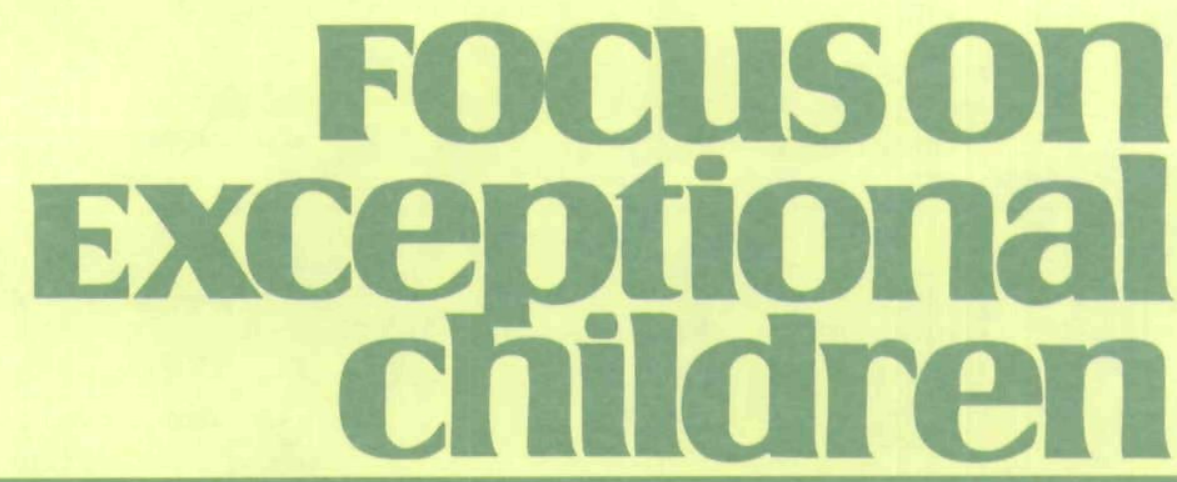

\title{
Implications of Mixed Reality and Simulation Technologies on Special Education and Teacher Preparation
}

\author{
Lisa Dieker, Michael Hynes, Charles Hughes, and Eileen Smith
}

As technology evolves, so does its impact on our lives. These changes clearly affect our daily activities, but how might they also impact education, teachers, and the lives of students with disabilities? This article focuses on technological innovations and their potential implications for students and teachers in our schools.

How changes in technology are impacting today's learners is highlighted by a study of youth ages 8-18 completed by the Kaiser Family Foundation (2004). The Foundation labeled and defined this age group as Generation M, youth who use multimedia daily. This new generation was found not to disregard older media but simply to be skilled at multitasking — using various types of media simultaneously (e.g., watching TV, text messaging, and playing an online game at the same time). In its research of more than 700 kids who journaled for 7 days about their use of media, the Kaiser Family Foundation found that:

\begin{abstract}
The typical 8- to 18-year-old lives in a home with an average of $3.6 \mathrm{CD}$ or tape players, $3.5 \mathrm{TVs}$, 3.3 radios, $2.9 \mathrm{VCRs} / \mathrm{DVD}$ players, 2.1 video game consoles, and 1.5 computers. Indeed, one in four $(24 \%)$ live in homes with five or more TVs, half $(53 \%)$ live in homes with three or more VCRs/DVD players, half $(56 \%)$ have two or more video game players, and one-third $(34 \%)$ live in homes with a digital video recorder. Cable or satellite TV service is widely available (more than eight in ten young people have one or the other), and a majority of youth $(55 \%)$ get premium channels such as $\mathrm{HBO}$ at home. (p. 5).
\end{abstract}

Generation $\mathrm{M}$ is exposed to and expects that technology will be part of daily life. Yet, these expectations create a gap between those who are students in today's schools and those who teach this generation of learners. We conjecture that there may be an even wider gap between higher-education professionals who are preparing these future teachers to serve Generation M students.

This article does not emphasize the problems that these gaps may create but, rather, the potential implications of these emerging technologies-which have tremendous potential for teacher educators, classroom teachers, and students with disabilities. The authors of this article come from diverse disciplines, representing a different type of team than one normally sees in the discipline of special education. This diversity is both necessary and natural when technology is applied to the educational needs of today's

Lisa Dieker, Michael Hynes, Charles Hughes, and Eileen Smith are affiliated with the University of Central Florida, Orlando.

Copyright $\odot$ Love Publishing Company, 2008 
children. Our team of colleagues across four disciplines came together to think and talk about new solutions to traditional problems in education.

Lisa Dieker is a faculty member in special education whose career has spanned general and special education, with a passion for working with secondary students in urban communities.

Michael Hynes, whose vision and partnership with the Lockheed Martin Corporation created the Lockheed Martin/UCF Academy for Mathematics and Science Teacher Education, provides insight into future preparation of teachers across disciplines.

Charles Hughes (not the Dr. Hughes who is prominent in the field of special education), well known for his work in computer science and simulation technologies, has provided insight from his extensive work in interactive simulation and computer graphics.

Eileen Smith contributes her experience with free-choice learning in science centers and her lifelong connection to artistic expression.

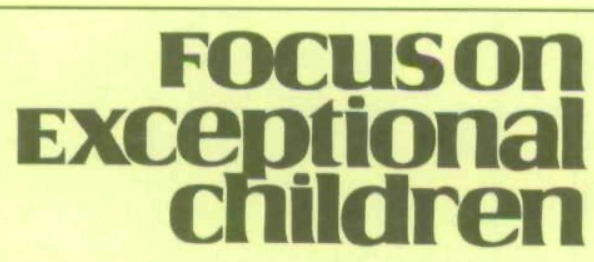

ISSN 0015-511X

FOCUS ON EXCEPTIONAL CHILDREN (USPS 203-360) is published monthly except June, July, and August as a service to teachers, special educators, curriculum specialists, administrators, and those concerned with the special education of exceptional children. This publication is annotated and indexed by the ERIC Clearinghouse on Handicapped and Gifted Children for publication in the monthly Current Index to Journals in Education (CIJE) and the quarterly index, Exceptional Children Education Resources (ECER). The full text of Focus on Exceptional Children is also available in the electronic versions of the Education Index. It is also available in microfilm from Serials Acquisitions, National Archive Publishing Company, P.O. Box 998, Ann Arbor, MI 48106-0998. Subscription rates: individual, \$42 per year; institutions, \$56 per year. Copyright (c) 2008, Love Publishing Company. All rights reserved. Reproduction in whole or part without written permission is prohibited. Printed in the United States of America. Periodical postage is paid at Denver, Colorado. POSTMASTER: Send address changes to:

$$
\begin{gathered}
\text { Love Publishing Company } \\
\text { Executive and Editorial Office } \\
\text { P.O. Box } 22353 \\
\text { Denver, Colorado } 80222 \\
\text { Telephone (303) 221-7333 }
\end{gathered}
$$

\section{EDITORIAL BOARD}

Lisa Dieker
University of Central Florida

Paula Maccini University of Maryland

Marleen Pugach

University of Wisconsin-Milwaukee

Carrie E. Watterson Editor
Stanley F. Love Publisher
This article outlines a partnership and vision for how existing and emerging knowledge and technologies could and should be applied to the field of special education. The synergy of our work comes from the collaborative nature of a university that was founded just over 40 years ago with an emphasis on simulation and technology (because of our proximity to NASA and other high-tech industries including Lockheed Martin, Siemens, Disney, and Universal) and has grown to become the sixth largest university in the United States. This collaboration at UCF is still challenging, yet possible. We are able to bridge our worlds in a place without academic silos, and hence our work is built upon our separate disciplines while using a transdisciplinary approach to learning, growing, and applying our knowledge-we hope, to make a difference for people with disabilities and teachers in the field of education.

What we propose in this article is to follow a Disney theme of attempting to "stimulate your imagination" with the emerging projects at UCF and to summarize how we see our work impacting special education and teacher education. Also, we mention potential future projects and paths that our partnership might consider. We center our collaborative work in mixed-reality environments (the blending of real and synthetic content) (Hughes et al., 2005), which we believe will become the way we do business in teacher education. No longer will we be immersed either in technology (such as a virtual reality world) or only in reality. Rather, we will see the blending of those two worlds, meeting the expectations of Generation M students while advancing education frontiers.

We will discuss how we potentially see advancements in technology impacting students' literacy and their functional and social skills, followed by a discussion of how these emerging tools can influence the future of teacher preparation, along with how mixed-reality environments have potential implications across teachers, students, schools, families, and society. We conclude with a look into the future, how free-choice learning environments will affect the way students learn and interact in multiple environments.

\section{FUTURE USES OF TECHNOLOGY FOR STUDENTS WITH DISABILITIES: LEVELING THE PLAYING FIELD}

As our field embraces the outstanding work of organizations such as CAST (www.cast.org) and the development of numerous assistive technology devices, we recognize the potential for technology to level the playing field for students with disabilities. Yet, in so many ways the challenge for any futuristic tools that are developed will be to combat fear and misunderstanding, much like what was required when the calculator, television, typewriter, and computer 
were introduced, causing many in society to believe that these tools would give unfair advantages to students with disabilities.

Over time, most states have come to accept the more traditional tools such as calculators and computers, especially with regard to neurologically based disabilities, just as has been true for some time with regard to physical disabilities, Yet, many parents and educators will have to continue to advocate for emerging technologies such as iPods that can read material to a student.

Fortunately, the National Instructional Materials Accessibility Standards (NIMAS) requires that all textbooks have to be in electronic format. With advocacy from parents, educators, and evolving standards, many other new technological advances will be available for day-to-day use and should be a part of students with disabilities' daily school experience. With the current generational gap related to technologies, many teachers and policymakers do not readily understand how these new tools can equalize student learning opportunities and outcomes.

One way to think about the potential changes that technology could bring to our field is to compare a statement that someone in special education may have made two decades ago and probably got a reaction of, "You must be insane," by stating, "Handwriting in 10 years will be an obsolete skill." This same type of statement could be at the tip of the iceberg right now, in relation to students and their ability to read printed material. We are not saying that students should be exempt from learning to "read" or possessing "skills" to assimilate new information, comprehend material, or process information, but that the art of reading print may not be the only way to read and understand material, much like handwriting is not the only means to express your ideas today. This statement does not mean that we believe the teaching of reading should disappear. Instead, it should mean that students who cannot or may never get their brains to process the written word be made to feel successful, much like those who used to not be able to write legibly can now function equally through keyboarding.

Because most new word processing platforms have builtin voice software, combined with the introduction of NIMAS standards providing material in electronic format, the solution for assisting struggling readers is already available. For students with print disabilities, just like the typewriter and computer leveled the playing field for writing, these tools could level the field of gaining knowledge from print for students with vision and neurologically based reading issues.

The question will continue to be, as it always has been: Will states, policymakers, and classroom teachers allow new technologies to level the playing field, or will these be considered inappropriate for students to show that they can learn new content in our nation's schools? This bias may exist even if students' eyes don't work or their brains don't process text like their peers in the seats next to them. Although we cannot predict the future, we can provide enticing ideas about the role of technologies for students with disabilities and the way we may see the future changing for these students, their teachers, and society in general.

\section{Technology and Life Skills}

One of the issues that students in general struggle with is the actual learning of social skills. This issue could be addressed in more traditional ways, such as working with peers, video modeling, or direct social skills instruction. Despite the potential usefulness and research to support each of these approaches, they all either lack the social context for generalization of the task or may even require at-risk students to learn new skills among intolerant peers. This lack of tolerance tends to be especially true during adolescence. As part of our work, we are open to any and all possibilities and see tools ranging from an online tool to an immersive environment as options for all students, but specifically for students with disabilities, to learn skills using tools that embrace the culture of Generation M.

\section{Examples of Formats}

For younger students, tools such as Club Penguin and Webkins provide formats to learn caregiving skills for a virtual pet and also social interaction in controlled environments with other pet owners. This fosters educational game play and also controlled interactions related to buying and selling goods, earning funds, and ensuring the health, happiness, and safety of their pets. Although at this point the research for these sites related to students with disabilities is limited, it does provide examples of the future tools that will be a natural part of the world for many students with disabilities to learn in multiple environments.

For slightly older students, the highly immersive and communicative world of Second Life has both a more controlled environment called Teen World and a traditional adult world. This site is already being reported as an effective social environment for many students with limited transportation or physical abilities, providing employment opportunities as well as a chance to go out and socialize with peers regularly. In a recent self-advocacy training session for young adults with Down syndrome, we found that it allowed them the freedom to communicate with others and to socialize in a virtual world.

Of course, all of these types of settings, such as MySpace, YouTube, and other such Internet sites, have their dangers and challenges. As part of our work with Generation $\mathrm{M}$, we propose educating students both on the social skills of life and on the social skills and safety of online 
environments. Not including students with disabilities in these types of environments means excluding students from an aspect of life and society that is not only a skill but also is a common point of conversation (e.g., text messaging) and development for nondisabled people in today's society. Beyond the use for students to gain skills from technology are the implications for teachers and potentially adults in more immersive environments.

\section{FUTURE USES OF TECHNOLOGY IN TEACHER EDUCATION}

How might technology impact teacher preparation? The need to recruit, prepare, and retool our teaching force in today's schools is well documented in the literature, especially in critical shortage areas such as special education. Although teacher preparation programs and alternative certification programs are available, most of these programs rely on traditional methods of preparing teachers to work in today's classrooms. These methods include college courses, field experiences, and some type of culminating student teaching. Despite the history and creative ways that colleges of education and school districts are working together to create these experiences, most beginning teachers still report that they feel inadequately prepared. This lack of preparation permeates the voices of beginning teachers in special education settings.

Our research team at UCF is looking at alternative methods with a specific concentration on teachers in urban classrooms. In partnership with the Haberman Education Foundation, we have created a virtual environment where prospective teachers and practicing teachers alike can interact with a group of virtual students. The initial prototype was developed in partnership with Simiosys, LLC, with an emphasis on behavior management-the number-one area of concern for most beginning professionals (Dieker, Hynes, Stapleton, \& Hughes, 2007). Our subsequent research has revamped the system's capabilities and ease-of-use/deployment with the ultimate goal of creating immersive simulated environments to recruit and prepare teachers in critical shortage areas.

In particular, we are starting to use this tool to assist beginning teachers in mathematics, science, and special education as they enter the teaching force. These three teaching fields are being targeted because of the critical shortages of teachers in these areas, with the virtual environment being available to support the recruitment, preparation, and retention of this workforce.

The need for these immersive environments in education is vital because of the growing disparity in cultural and ethnic backgrounds between the students who attend public schools in the United States and their teachers. The United States faces a critical shortage of effective and equitable educators for our diverse school-aged learners (Leavell, Cowart \& Wilhelm, 1999; Zeichner, 2003). Many urban school districts - those with high rates of poverty and, all too often, large minority populations - suffer most from shortages of qualified teachers (Darling-Hammond \& Green, 1990; Ingersoll, 2001; Riley, 1998; Zeichner, 2003).

While virtual technology for training has had a long history in fields such as medicine and the military, the application of emerging and innovative technologies in teacher preparation and education has been limited. The purpose of the virtual teaching environment (TeachMETM: Teaching in a Mixed Reality Environment) is to positively impact teacher recruitment, preparation, and retention in education by allowing teachers to hone their skills with virtual children, providing a more ethical approach to learning the art of teaching. Current and past practices in teacher education are filled with prospective teachers interacting with school children as if they were the "real teacher." These novice teachers often do not teach effectively. They frequently make content errors or have classroom management difficulties. The experience for students in these cases does not foster intellectual growth or affect the ongoing classroom behavior in a positive manner.

We are using real students to help novices become better. In a virtual teaching environment novice teachers can make mistakes without impacting real students, and they can repeat the experience without the students' remembering the initial encounter.

Developing effective educators is a priority for ensuring that future generations learn successfully in the classroom. Along with educator quality there is a need to reduce attrition in educator ranks from prospective teachers' not understanding the learning environment they will be entering. A growing body of evidence indicates that attrition is higher for those with little initial preparation (Darling-Hammond \& Sykes, 2003). For example, analysis of the Schools and Staffing Survey (SASS) data for 1999-2000 showed large differences in teachers' plans to stay in teaching between first-year teachers who felt well-prepared versus first-year teachers who felt poorly prepared.

Other research showed that novice teachers were much more likely to quit than their experienced counterparts were (Ingersoll, 2001), that attrition rates were about $50 \%$ higher in poorer schools than in wealthy schools (NCTAF, 2003). Other data trends show strong evidence that middle school and high school teachers are more likely than elementary teachers to leave their jobs (Allen, 2005). Turnover also is influenced strongly by academic field; specifically, special education, mathematics, and science teachers have the 
highest turnover rates (as examples, see Boe et al, 1997; Grissmer \& Kirby, 1992; Murnane et al., 1991). Armed with specific preparation, teachers may feel more equipped and willing to stay in the classroom longer (Whitworth, 2000), especially if the right teachers are selected and are provided strong preservice training. Most researchers report that quality teachers with more preparation have a greater chance of survival in the classroom (Blair, 2003).

At the core of the TeachMETM Lab are the lessons learned from research about teaching in inclusive classrooms, effectively delivering algebra instruction, and applying this knowledge to practice within these realistic simulated scenarios. Teachers must implement instructional practices that work. Using evidence-based practices is crucial to the educational success of students, particularly students in urban schools. Federal legislation (No Child Left Behind) requires that evidence-based practices be used to promote standardsbased student learning outcomes.

In this age of standards-based curricula and high-stakes testing, students' success depends upon teachers' providing instruction that promotes academic and social success based on varied learning needs. At the core of this issue for beginning teachers is the challenge of positively managing students while learning to teach from an inquiry-based approach. For the purposes of this research, we are using as the definition of inquiry:

\footnotetext{
...the creation of a classroom where students are engaged in (essentially) open-ended, student-centered, hands-on activities. Students investigate natural phenomena, using their background knowledge and experiences. The things students do include posing questions, solving problems, and creating answers or tentative generalizations. (Colburn, 2006)
}

For this reason, we began with a "behavioral virtual environment" that provides novice and practicing teachers the opportunity to "manage" classroom behavior where failure does not influence the learning of real students.

Our research now has added layers of inquiry-based instruction directed at common misconceptions in beginning algebra. This work reflects recommendations of the National Council of Teachers of Mathematics (NCTM), which issued a revised Principles and Standards for School Mathematics (PSSM). Although this document was worded carefully to avoid controversy about pedagogy, PSSM emphatically calls for learning with understanding, and it takes the position that students "learn more and learn better when they can take control of their learning by defining their goals and monitoring their progress" (p. 21).

The ultimate goals of our work are to increase studentlearning outcomes and to improve the recruitment, preparation, and retention of teachers. We propose ongoing and multiple TeachME ${ }^{\mathrm{TM}}$ Lab "field" experiences that are consistent for numerous beginning teachers. Virtual environments that deliver consistent experiences where preservice and induction teachers learn new skills represent a grounded method to measure teacher readiness and teacher mastery of critical components of the craft. Advanced technologies will continue to offer more uniformity, as well as increase the use of validated methods to improve teacher preparation and learning experiences.

Our next step is to form a research environment for teacher education (preservice and inservice) in algebra misconceptions, based on the work in the TASC project of Boston College (http://www.bc.edu/intasc). We will blend algebra content knowledge and misconceptions with the theories of learning and teaching from Maslow and Colbert, along with the work of Dreikurs (1968) and Long (1975) on behavioral principles, all having a strong scientific research base in the educational literature. The simulated environments we are creating will concentrate on teachers' clearly understanding behavior, diversity, disability, and effective instruction related to algebra misconceptions. Unlike research in actual classrooms, where controlled data collection is difficult to ascertain, this virtual environment enables consistency in preparation, immediate feedback, and ongoing data collection, as well as refinement of the environment to ensure the maximum impact on teacher performance and student learning.

Overall, teachers need added support during their induction year, and they cite classroom management as the primary area in which they need support (Portner, 2005). Developing ways to further teachers' classroom management skills while learning the art of teaching strong content to increase their effectiveness at working with students in the classroom allows them to focus on teaching and learning simultaneously.

At present, there are simply not enough individuals in the teacher pipeline, and many programs fall short of preparing and recruiting them. Relying on existing programs alone to recruit new teachers is simply inadequate if these teachers enter the classroom and leave after only one to two years because of their inability to master the art of teaching and managing a learning environment (Portner, 2005). The novel approach of a mixed-reality-based realistic classroom experience addresses how to improve the effectiveness of managing adolescent behaviors while increasing students' time on task and teachers' instructional time in a way that does not put real students at risk. Next we provide the theoretical underpinning of our development and a rich discussion about how the emergence of this new technology must be supported by sound theoretical frameworks of past research that embraces the human dynamics of the learner and the art of being a teacher to engage this range of learners. 


\section{Development of Virtual Environments in Teacher Education}

We are living in an interesting time. In this age of accountability, there is an attempt to make teachers accountable for each child in the classroom learning a prescribed body of knowledge. Further, each child must be able to demonstrate, in a prescribed manner, that he or she has learned a certain concept or mastered a certain skill. Simultaneously, educators are telling teacher education programs that each prospective teacher needs early and sustained experiences with children in the classroom. Herein lies the conflict. Teachers are becoming reluctant to give pre-professionals opportunities to learn on the job-apprentice, if you will-because teachers are being held accountable for student learning. Teachers are fearful that the time they are not teaching - when the teacher education students are teaching - may be detrimental to students' attaining stated learning goals, with consequences to the teacher.

From another point of view, some argue that the use of "practice teaching" by pre-professionals is not ethical-not ethical in the sense that highly qualified teachers are suspended from teaching children during student teaching. These paid professionals are sitting on the sideline while novices try to teach with their limited knowledge of how students learn and appropriate pedagogy for teaching a concept or skill. Early and sustained practice teaching in schools with real live children in a classroom is becoming more difficult to accomplish because of these intertwined pressures.

Is there an answer to this conflict between teacher accountability and good practices in teacher education? The answer may come from the world of technology. In many other fields the use of techniques in modeling and simulation has enabled people to learn new skills effectively. This same technological tool may be of use in teacher education as well.

Imagine that you walk into a room where everything looks like a middle-school classroom filled with children, but it is a virtual setting and the students in the classroom are virtual avatars. You can talk with the virtual students; they can show you their homework; and they may act like typical or not-so-typical students. A teacher can manage the classroom, teach students any subject, and monitor their progress in learning. In an environment like this, prospective teachers can learn the skills of their profession and practicing teachers can hone their skills. If novice teachers make mistakes or if experienced teachers want to experiment with a new teaching idea, it poses no danger to the learning of any real student. If a novice makes an error, he or she can reenter the virtual classroom and try again to teach the same students the same concept or skill. All of this is possible without impeding the learning of any real child.
The development of a simulated virtual teaching environment must be based on the best knowledge and understanding of the physical features of a typical classroom, the socioeconomic context of the school, and the nature of preadolescent children maturing into adolescents. Understanding the socioeconomic context for a given school and the physical attributes of a classroom are not the challenge, and these can be added to a simulated environment with some sense of reality. Rather, the challenge is to portray simulated middle-school students - students who are transitioning from pre-adolescence into full-fledged adolescence. These virtual students must seem like real middle-school students who exhibit common learning problems and learning disabilities, and teachers using a virtual classroom have to be able to correct their misconceptions or help students learn in spite of learning differences. Both of these challenges in developing a virtual classroom-portraying realistic students and making them spontaneously interactive- must be met prior to having a fully functional TeachMETM Laboratory.

\section{Portraying Realistic Middle School Students}

Adolescence is a time of many transitions physically, cognitively, and socially. Although all pre-adolescents develop across all three of these domains, they don't all follow the same timeline. Also, a specific child does not follow a direct path from pre-adolescence to adolescence. Surges in maturity, particularly cognitive and social maturity, are often followed by regression to earlier patterns. It is often said that an adolescent is a caricature of his or her adult self. Before looking at how we know what we do know about adolescence, we should refresh our memories, in a nontheoretical way, about what we do know about adolescence. Teen development can be divided into three stages: early, middle, and late adolescence. The normal feelings and behaviors of adolescents for each stage are described by the American Academy of Child and Adolescent Psychiatry (Pruitt, 2000), as follows:

Early Adolescence (12-14 years)

Movement Toward Independence

- Struggle with sense of identity

- Moodiness

- Improved abilities to use speech to express oneself

- More likely to express feelings by action than by words

- Close friendships gain importance

- Less affection shown to parents, with occasional rudeness

- Realization that parents are not perfect; identification of their faults

- Search for new people to love in addition to parents

- Tendency to return to childish behavior

Career Interests

- Peer group influences interests and clothing styles

- Mostly interested in present and near future

- Greater ability to work 
Sexuality

- Girls ahead of boys

- Same-sex friends and group activities

- Shyness, blushing, and modesty

- Show-off qualities

- Greater interest in privacy

- Experimentation with body (masturbation)

- Worries about being normal

Ethics and Self-Direction

- Rule- and limit-testing

- Occasional experimentation with cigarettes, marijuana and alcohol

- Capacity for abstract thought

Middle Adolescence (14-17 years)

Movement Toward Independence

- Self-involvement, alternating between unrealistically high expectations and poor self-concept

- Complaints that parents interfere with independence

- Extremely concerned with appearance and with one's body

- Feelings of strangeness about one's self and body

- Lowered opinion of parents, withdrawal of emotions from them

- Effort to make new friends

- Strong emphasis on the peer group

- Periods of sadness as the psychological loss of the parents takes place

Career Interests

- Examination of inner experiences, which may include writing a diary

- Intellectual interests gain importance

- Some sexual and aggressive energies directed into creative and career interests

Sexuality

- Concerns about sexual attractiveness

- Frequently changing relationships

- Movement toward heterosexuality with fears of homosexuality

- Tenderness and fears shown toward opposite sex

- Feelings of love and passion

Ethics and Self-Direction

- Development of ideals and selection of role models

- More consistent evidence of conscience

- Greater capacity for setting goals

- Interest in moral reasoning

Late Adolescence (17-19 years)

Movement Toward Independence

- Firmer identity

- Ability to delay gratification

- Ability to think ideas through

- Ability to express feelings in words

- More developed sense of humor

- Stable interests

- Greater emotional stability

- Ability to make independent decisions

- Ability to compromise

- Pride in one's work

- Self-reliance

- Greater concern for others
Career Interests

- More defined work habits

- Higher level of concern for the future

- Thoughts about one's role in life

Sexuality

- Concerned with serious relationships

- Clear sexual identity

- Capacities for tender and sensual love

Ethics and Self-Direction

- Capable of useful insight

- Stress on personal dignity and self-esteem

- Ability to set goals and follow through

- Acceptance of social institutions and cultural traditions

- Self-regulation of self-esteem

(Pruitt, 2000)

The American Academy of Child and Adolescent Psychiatry has provided these descriptions of adolescent development, which resonate with our own development and the development of young people in our families or in our classrooms and neighborhoods. This common knowledge about adolescence has theoretical foundations that are important to a more complete understanding of adolescence and support the development of simulated adolescents for a virtual classroom. The work of Freud, Piaget, Erikson, Kohlberg, and Maslow have all contributed significantly to our understanding of adolescence, and their work is well documented in many other sources. We highlight two researchers, William A. Long and Rudolf Dreikurs, here, because their theories assisted us in the final stages of constructing a schema for creating virtual middle school students.

\section{William Long}

William A. Long, Jr. is an M.D., a pediatrician specializing in adolescents. Through his work, he formed a classification of adolescent personalities that earned him the 1982 "Outstanding Achievement in Adolescent Medicine" from the Society for Adolescent Medicine. The theory that developed from his research focuses on adolescence as a period of ambivalence-the coincident existence of conflicting feelings at any given point in time. "At this time in life, these young people are seeking independence, but are retaining some of their dependence on their parents." (Long, 1989, p. 2 ). Thus, they have ambivalence or conflicted feelings about many of their situations. This position is consistent with that of the American Academy of Child and Adolescent Psychiatry in its general descriptions of developing adolescents. The movement toward independence is one of the categories of descriptors used by the Academy.

Long recognizes that adolescence begins early (ages 9 or 10 ) and extends through the teens.

As emotional growth proceeds, we find that as the midpoint is approached in adolescence [age 15], ambivalence mounts, 
simply because there is an equal mixture of dependency and independence. (Long, 1989, p.3)

A graph of ambivalence would show that conflicting feelings about independence increase from the beginning of puberty until about age 15 . After age 15 the ambivalence gradually subsides as the child becomes a more independent young adult. The resulting curve would look something like a bell curve. Of course, this picture does not describe every child's development precisely. Some go through it more intensely and quickly than others, and some more smoothly than others. Some children seem to take forever to reach independence. Maturation, according to Long, is not always a direct path.

What Long has described is the normal growth and development of a child. The teacher's responsibility is not to exacerbate the spurts and regressions along the path to maturity, especially for students with disabilities. To the contrary, teachers should be helping to remove obstacles in the maturation pathway, to smooth the line of maturity. In helping students through the maturation process, teachers must understand that different personalities have different obstacles and that sometimes other people place obstacles in their pathways. Divorce of parents, bullying by another student, and an incorrect behavior management decision by a teacher are examples of obstacles that can cause regression along the ambivalence curve.

Individuals tend toward one of four behavior types, which can be augmented with zero to four ancillary traits (Dziuban, Moskal \& Dziuban, 2000). These behavior types are formed as a result of the intersection between psychological energy level and the need for approval: Aggressiveindependent, aggressive-dependent, passive-independent, and passive-dependent - as illustrated in Figure 1.

Long (1989) posits that aggressiveness denotes the energy level that adolescents bring to learning environments. That is, aggressive types typically show high energy levels and passive types show little energy. Dependency, by

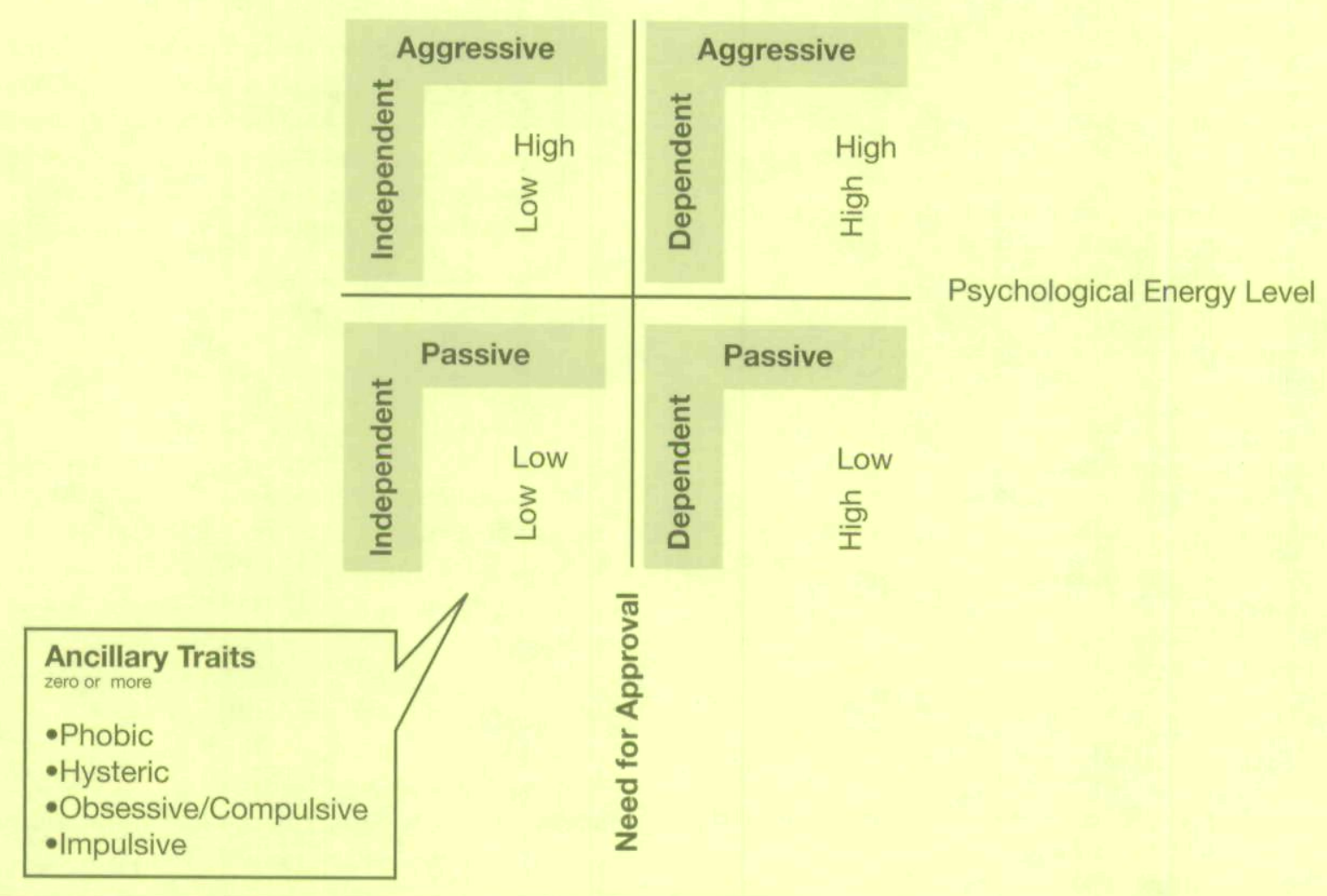

Source:Virtual Character Theoretical Framework, by B. DaCosta, unpublished paper, University of Central Florida, Media Convergence Laboratory, 2007. 
contrast, deals with the need for approval of authority. Dependent types seek approval, which affects their behavior in learning situations. Dependent students will perform less than meaningful learning tasks to get the approval of a teacher, whereas independent students will not.

The aggressive/passive dimension, along with the independent/dependent dimension, produces a $2 \times 2$ figure that describes four personality types that can be extended by four ancillary traits. For example, an aggressive-independent student may exhibit impulsive behavior. The four ancillary traits-phobic, hysteric, obsessive/compulsive and impulsive - may be attached in any number to any of the personality types expressed on an intensity continuum from none to severe. Thus, many different virtual students can be created from this relatively simple matrix.

The framework that Long (1989) has provided serves as an ideal way to think about creating virtual students for the virtual classroom. The four generic personalities-aggressiveindependent, aggressive-dependent, passive-independent, and passive-dependent-augmented by the four ancillary traits in different levels of intensity provide a wide variety of personalities for students in a classroom as in real life.

\section{Rudolf Dreikurs}

Rudolf Dreikurs graduated from the medical school of the University of Vienna. He left Austria before the Nazis arrived and came to the United States in 1937. He moved to Chicago in 1939 and remained there until his death on May 25, 1972. Dreikurs was Professor Emeritus of Psychiatry at the Chicago Medical School and Director of the Alfred Adler Institute of Chicago. His research in the field of social psychiatry led him to develop a pragmatic method for understanding the purposes of reprehensible behavior in children. He believed that children's misbehaviors could be understood by recognizing the goals of the child. The four goals of misbehavior, according to Dreikurs, are: attention getting, power and control, revenge, and helplessness and inadequacy.

Attention getting. Attention getting is identified as behavior in which a student disturbs the class or part of the class. Often, attention getting is manifested because students are not getting the recognition that they feel they deserve. When students do not get positive attention for their positive behaviors, they will seek any attention by disturbing-type behaviors. "Students who seek attention should not receive it when they act out. To give attention to the student for inappropriate behavior would be playing into the student's plan and would not help the student learn how to behave productively in the group" (Wolfgang 2001 p. 120).

Power and control. Students who are motivated to misbehave because of power and control issues will behave repetitively in a manner to make them the center of attention.
When the teacher tries to get the behavior to cease, the students may become defiant, escalate the misbehavior, and challenge the teacher. Wolfgang (2001) asserts:

\begin{abstract}
A student who wishes to possess power should not be able to engage the teacher in a struggle. The teacher who falls for this "bait" and gets pulled into the battle is merely continuing the excitement and challenge for the student. The student becomes increasingly bolder and pleased with trying to test the teacher. The teacher should attempt to remove the issue of power altogether and force the student to look for some other goal for behaving. (p. 121)
\end{abstract}

Revenge. Students who feel they have been treated unfairly often retaliate to get recognition. The students often are motivated by revenge after many failed attempts to get attention through power and control.

\begin{abstract}
In this case, the teacher is dealing with a more difficult task. A student who feels hurt and wishes to retaliate must be handled in a caring, affectionate manner. It is likely that this student appears unloving and uncaring, and is very hard to "warm up to." But this is exactly what the student needs-to feel cared for. (Wolfgang, 2001, p. 121)
\end{abstract}

Helplessness and inadequacy. Students who are motivated by helplessness and inadequacy often go unnoticed by the teacher. They may sit silently and engage in no interaction, passively refuse to participate, or request to be left alone. They may refuse to comply with classroom rules or to even try in learning activities.

\footnotetext{
[Students who show] inadequacy or helplessness are the most discouraged. They have lost all initiative of ever trying to belong to the group. The teacher must exercise great patience and attempt to show [these children] that they are capable. (Wolfgang, 2001, p. 122)
}

Dreikur's work is linked with Long's theory of adolescent personality. Aggressive-independent students in Long's model are more likely to misbehave because of attention getting or power and control and less likely to misbehave because of helplessness and inadequacy. Likewise, a passive-dependent student is more likely to be motivated to misbehave using helplessness and inadequacy actions than any others. The work of Long and Dreikurs provides the most critical information for developing virtual middle school students, but we must not lose sight of Freud, Piaget, Kohlberg, Erikson, and Maslow as providing much of the early knowledge about adolescent development. The following attributes were used to create virtual students for the TeachME ${ }^{\mathrm{TM}}$ experience.

\section{Attributes of Adolescents}

- Gender: Male or Female

- Age: 12-14; 14-17; 17-19 (American Academy of Child and Adolescent Psychiatry) 
- Sibling order: only child, rank in sibling order, stepsibling or half-siblings, adopted

- Ethnicity: African-American, Hispanic, Asian, Caucasian

- Language: English or ESL

- Learning Disability: issues with "oral expression; listening comprehension; written expression; basic reading skill; reading comprehension; mathematics calculation; or mathematics reasoning"

- Socioeconomic Status: Lower, Middle or Upper

- Personality Type: Aggressive-Independent, Aggressive-Dependent, Passive-Independent and PassiveDependent (Long)

- Ancillary Traits: Phobic, Impulsive, Obsessive-compulsive or Hysteric (Long)

- Misbehavior Motivation: Attention Getting, Power, Revenge and Control, Helplessness and Inadequacy (Dreikurs)

- Movement toward Independence: There are no categories for this attribute, but this is the place where much ambivalence is shown about expectations of one's self as well as relationships with peers and parents. (American Academy of Child and Adolescent Psychiatry, Piaget, Kohlberg, Erikson, and Long)

- Sexuality: The three main areas of concern for students in this category are: concerns about sexual attractiveness, the stress of frequently changing relationships with others, and the individual's movement toward heterosexuality with accompanying fears of homosexuality. (American Academy of Child and Adolescent Psychiatry, Erikson, and Freud)

- Ethics and Self-Direction: Students are concerned about their development of ideals and selection of role models; they seek more consistent evidence of conscience in their actions; they want a greater capacity for setting goals; and they are gaining interest in moral reasoning. (American Academy of Child and Adolescent Psychiatry; Kohlberg)

A script writer developing a virtual student for the TeachMETM experience can now select attributes for any student. Consider the following examples:

- The student in seat 1 of row 1 is a 15 -year-old Mexican female of a recent immigrant family (low socioeconomic) who speaks English words but finds sentences difficult. She appears to have a PassiveIndependent personality, exhibiting helplessness when given a grade-level learning task. Because of her recent arrival in the United States and her limited English skills, she is tied more closely to family than peers. She is attractive but shies away from boys. Her role model is her mother.
- Another student, in seat 4 of row 3, is a Caucasian boy (age 14) whose parents are both teachers at another school. He is known to be involved in youth football because he wears his jersey to school on Fridays. His personality is Aggressive-Dependent with no apparent ancillary traits. If he misbehaves, it usually involves trying to get attention from his peers or the teacher. He has many friends among the boys and is beginning to talk to girls in a teasing manner.

- A third student is a Passive-Dependent type student. She is 14 years old, immature physically, and struggles with learning tasks. She is constantly seeking attention from the teacher by feigning helplessness and inadequacy or by approaching the teacher quietly and shyly. She consistently volunteers for work tasks in the classroom when the teacher needs assistance.

Each of these students is unique. At the same time, they are alike in many ways in that they are striving to work their way through this difficult time in life. Because they are different in many ways, too, they will react to situations in the classroom differently. Teachers must be capable of discerning the needs of these adolescent students because ultimately the teachers must teach content to the students. Teachers will not be successful if they teach content to students without that connection. They must know their students first.

Using the attributes of adolescents in this review, developers of virtual students can create classrooms of virtual students that can act according to their indicated attributes. By choosing students with specific attributes, a classroom from an urban setting can be created, or a classroom from a rural community can be developed. Using the attributes of adolescents together with the research on facial expressions, body language, motion capture, and artificial intelligence, developers will be able to create virtual classrooms that are realistic tools in teacher education.

\section{THE USE OF VIRTUAL ENVIRONMENTS IN ASSESSMENT AND ASSISTANCE FOR STUDENTS AND PROFESSIONALS}

At UCF we are developing other immersive virtual reality environments that can be used to support students. The potential is endless for these environments to be used to sensitize students with disabilities to learn in new environments, to teach vocational training, and to assist in various skills. As the cost of the technology decreases, the potential for these tools in the field of education increases.

The term Virtual Environments (VE) is an inclusive one that comprises all systems and experiences in which a user interacts with virtual objects. Mixed Reality (MR) refers to 
the broadest form of a VE experience in which virtual assets (typically visual and aural, but occasionally involving touch, smell, and taste) are blended with real assets. The TeachMETM experience we have already discussed has just one real element outside the participant, and that is an interactor who digitally puppeteers the behavior of a selected virtual student through voice, motion, and facial expression. Everything else about the classroom experience is synthetic. The technical infrastructure, however, is what gives life to this primarily virtual experience.

\section{Interactors}

An interactor is a person trained in acting, improvisation, and human psychology. Interactors from UCF's Interactive Performance Lab are pioneers in live simulation for entertainment, training, and education. They are renaissance artists who develop live, human-to-human, interactive story experiences. They facilitate a non-actor's natural capacity to play in a virtual context. Unlike typical acting, which is based on scripts, and improvisation, which is based on response to an immediate environment, interactors develop a character and then play out that character's behaviors based on family history, ethnic and political identity, living environment, personal motivations, friendships, and so on.

In the virtual classroom the interactor provides the deep, human, interpersonal behaviors that artificial intelligence is still incapable of producing. Each time the teacher approaches a virtual student, the interactor "jumps into the skin" of the character, giving it life and personality. The motions and the expressions, nonverbal and verbal, of the interactor are transferred to the virtual student. One interactor can "puppeteer" all the members of a small classroom, exhibiting the wide variety of behaviors seen in a "typical" classroom. The physical appearance of the interactor (age, gender, ethnicity) is not seen by the person in front of the classroom; the virtual student is what is seen. This use of an interactor is key to our teachers-in-training feeling that the experience is real rather than a game.

\section{Virtual Students}

The classroom, which a teacher observes on the screen he or she is facing, is synthetic, as are the students who inhabit that classroom. Though synthetic (or virtual), each student has a unique and appropriate personality for a member of the school population we wish to present to the teacher-intraining (trainee). When the trainee stands back in a typical lecturer's position, the virtual students express behaviors that are controlled by computer software we have developed. These behaviors are based on the personality types identified by Long and Dreikur, and each specific child's detailed backstory and personality was developed by one of our interactors.
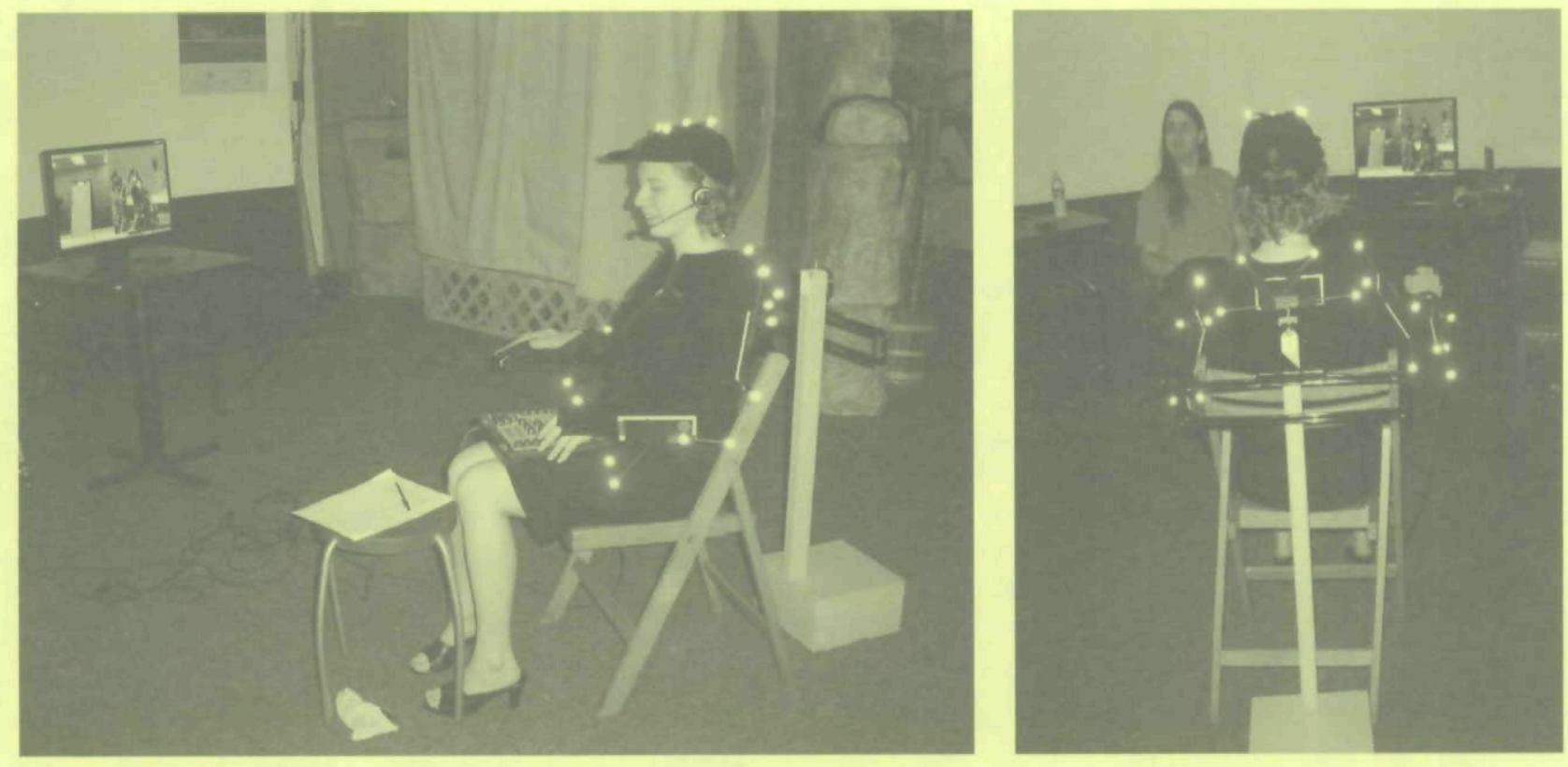

FIGURE 2

Inter-actors puppeteering virtual student behaviors. Inter-actor's wrist and head are tracked to control animation of virtual students whom the teacher is directly addressing. Glove on inter-actor's hand is used to lip sync. All other virtual students have Al-controlled behaviors. 
In effect, an interactor guided our programming of the automated behaviors of one (or more) of the virtual students. These virtual students tend to get more rowdy or more withdrawn (depending on the character's attributes) when the trainee ignores them as individuals or shows little understanding of their personal motivations. Increases in the level of chaos also can be controlled by a trainer or even an interactor.

As pointed out above, one interactor is employed each time we run a trainee through the system. That interactor puppeteers the character (if any) currently being addressed by the trainee while delivering instruction in mathematics. If the interactor observes that the trainee is not showing respect to or understanding the virtual students' academic or social needs, the interactor can ratchet up the behaviors of that character's friends. Once this happens, the artificial intelligence underlying the virtual students' automated behaviors typically causes the discordance to rise slowly, but ever so surely, across the entire class.

This combination of automated, semi-automated, and interactor-controlled behaviors is what gives life to the TeachMETM experience, causing many trainees to think they spent a half hour in instruction when the exercise typically lasts only 5 minutes. Based on the development of this current work and past development at UCF, other tools are emerging that are potentially relevant to individuals who have learning and/or behavioral differences.

The current simulation experiences have evolved from the Media Convergence Laboratory (MCL) at UCF, which takes ideas from concept to physical reality. MCL has developed a number of systems of use to populations of students and adults with special needs. Some examples are found in Fidopiastis et al. (2006), Hughes et al. (2005), and Stapleton and Hughes $(2005,2006)$. In this article we provide a sample of these tools - a virtual kitchen for rehabilitation, a virtual restaurant for stuttering, and a virtual warehouse for post-traumatic stress disorder (PTSD) - all utilizing a mixed reality environment much like the TeachME ${ }^{\mathrm{TM}}$ experience, allowing safe and repeated learning and growth in naturalistic settings.

\section{Assessing and Improving Performance}

Overall, the concepts developed and tested at UCF in the $\mathrm{MCL}$ are based on the hypothesis that performance assessment and improvement are most effective in contextually meaningful settings. A common issue in the field of special education is the lack of skill transfer from one setting to another. Providing instruction in contextually meaningful settings means that, in the extreme, people have to undergo assessment and rehabilitation in their places of work or in their homes - the venues in which they will carry out the tasks for which they are being trained. Of course, that is unreasonable. Few corporations can shut down normal operations while a therapist works with an impaired employee; few families can afford to hire a therapist to spend significant amounts of time in their homes. Further, carrying out assessment and rehabilitation on the job or at home during early stages of therapy can expose individuals to dangerous situations, especially those who are cognitively impaired.

We posit that the key to providing a safe, effective assessment/training environment is through the ability of MR to take generic physical objects and have them take on personalized appearances. To do so, we first must capture 3-D imagery of the familiar objects-for example, of someone's kitchen counters, floor, cabinets, and so on. Where appropriate, we also must capture the audio signature of the area, even to the extent of capturing the sound of cars passing by or of phones ringing.

Once the familiar setting is captured, we have to move around the generic props (e.g., low- cost kitchen or service counters) to achieve the correct spatial layout. This contextual representation has to be tested against the 3-D models captured previously to be sure that, when properly registered, the virtual objects (e.g., kitchen cabinets, office supply racks, or restaurant tables) can be aligned with their physical counterparts. We have found that minor scaling and orientation errors seem not to be noticeable, so some issues can be accommodated by simple model translations.

Once the familiar setting has been created, we have to include other virtual assets and behavior scripts. Fortunately, most, if not all, of these will be the same for large numbers of individuals. As examples, in a restaurant scene we may want virtual waiters scurrying about, and in a warehouse we may want the sounds of traffic passing by and the hustle of forklifts moving inventory around.

\section{Scenarios}

The following are three scenarios we have developed: the MR kitchen, the MR restaurant, and the MR supply depot. Each of these tests the concept of using MR to create familiar surroundings, and each addresses a different problem of assessment and/or rehabilitation that applies to the needs of students with disabilities as well as to prepare a new force of educators and therapists to work in these types of environments.

\section{The MR Kitchen}

Using MR in cognitive rehabilitation was first tested with a participant who had memory impairment resulting from an aneurism (Fidopiastis et al., 2006). For this study a depth camera (3DV Systems DMC100) and a 3D laser scanner (Riegl LMS420i) were used to capture dimensions and visual characteristics of the participant's home kitchen. The resulting personalized setting for making breakfast provided 

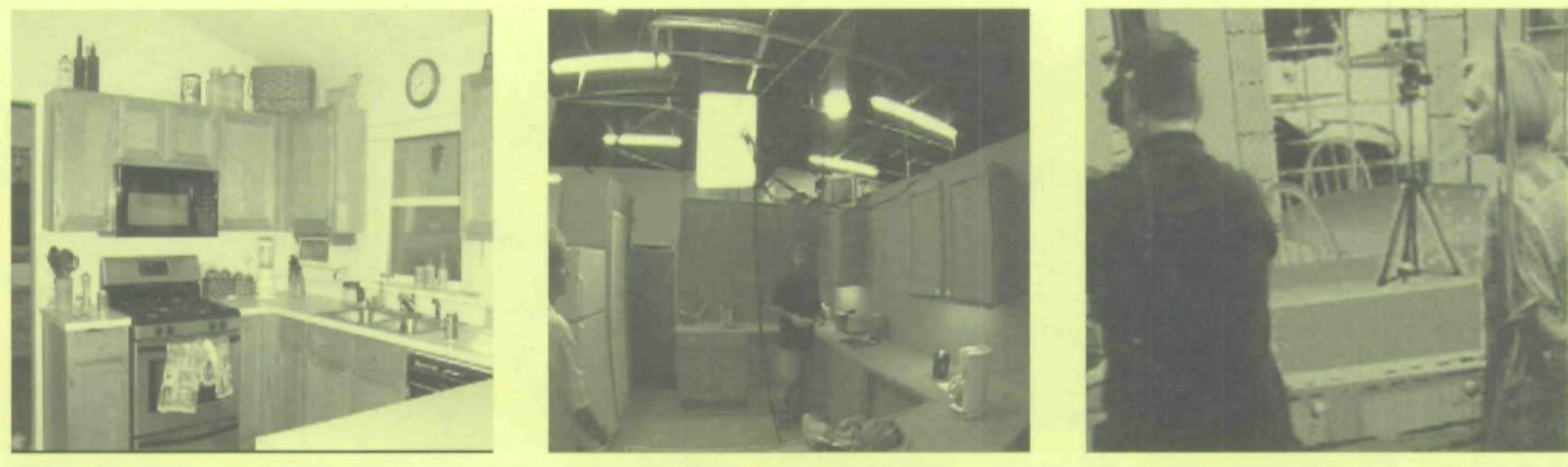

FIGURE 3

(a) The participant's kitchen was captured; (b) modeled in a MR environment; and (c) then experienced by the participant making breakfast in the MR kitchen.

the context for the therapeutic environment. The process of creating a personalized experience is shown in Figure 3.

Results from the study shown in Table 1 demonstrate that, after five training sessions, the participant with anterograde amnesia improved his time in locating all the items necessary to make his own breakfast. His time actually came close to that of his wife, who took just over a minute to make the same breakfast both in her home and in the MR kitchen.

The more interesting aspect of this study is that the best performance for the participant was in his own home after the training was complete. The posttest results demonstrate that the mixed reality training supports transfer of learning to the home environment, increasing the potential for longlasting positive therapeutic outcomes.

An added benefit of MR is the capability of incorporating novel data-collection methods. For example, during the MR kitchen breakfast-making task, motion capture sensors were able to track the participant while he traversed the kitchen. These data were visualized using "after-action review," a term that refers to the process of reviewing an experience from multiple points of view (e.g., that of the patient or of an observer) and at multiple levels of detail (e.g., replaying every frame or just those that reflect major tasks such as acquiring a specific object). Figure 4(a) shows the path that the participant took during the first MR session. The results are similar to the participant's performance during the pretest at home. The more concise path taken during the last training session was also replicated during the posttest, providing further support that the participant was transferring knowledge to his home environment.

Although the data shown in Figure 4 suggests a change in the participant's behavior between the first and last exposure in the MR training environment, no metrics are available to correlate this change specifically with biophysiological

TABLE 1

Amount of Time to Locate Target Items in Seconds and Total Time to Complete Breakfast Preparation

\begin{tabular}{llrrrrrrr}
\hline Location & Target & Pre & VE 1 & VE 2 & VE 3 & VE4 & VE 5 & Post \\
\hline Pantry & Cereal & 58 & 112 & 76 & 119 & 80 & 18 & 8 \\
Cabinet & Bowl & 13 & 38 & 26 & 43 & 28 & 27 & 18 \\
Refrigerator & Milk & 14 & 44 & 24 & 12 & 7 & 14 & 14 \\
Drawer & Spoon & 3 & 15 & 15 & 3 & 6 & 5 & 3 \\
Counter & Make cereal & 73 & 120 & 84 & 41 & 40 & 37 & 51 \\
& & & & & & & & \\
& Total Time (s) & 240 & 379 & 315 & 341 & 236 & 177 & 158 \\
& Total Time (m:s) & $4: 00$ & $6: 19$ & $5: 15$ & $5: 41$ & $3: 56$ & $2: 57$ & $2: 38$ \\
\hline
\end{tabular}



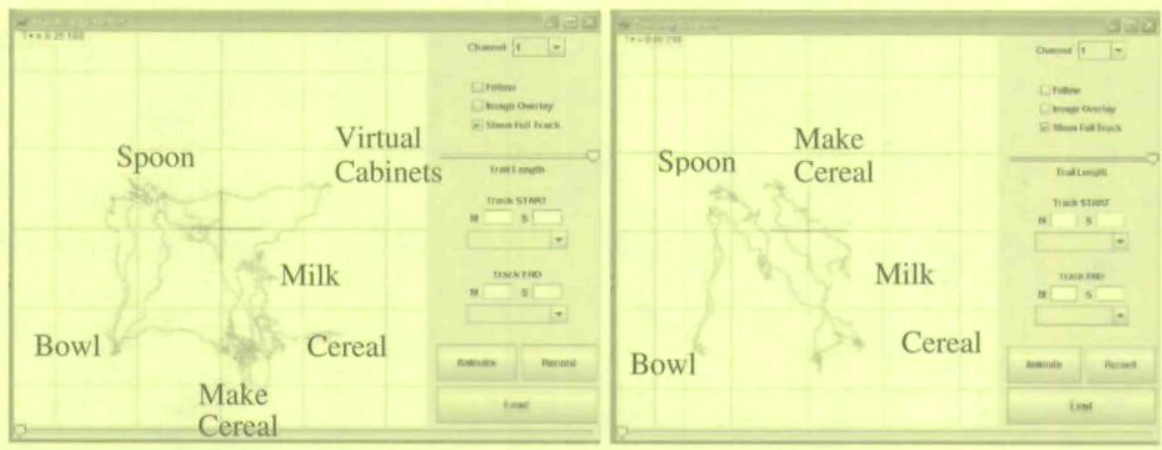

FIGURE 4

(a) Tracker Reviewer data displaying the participant's retrieval pattern of bowl, spoon, milk, and cereal in the first VE training session; (b) Tracker Reviewer data displaying the participant's last VE training session for this same task.

changes in the participant. As a consequence, the authors purchased equipment that could have been used to determine if such changes might be occurring. That will be used in subsequent studies and was, in fact, employed in the experiment that follows - an experiment that applies to students with disabilities as well as to those with speech impairments.

\section{The MR Restaurant}

When treating people who stutter (PWS), speech therapists have employed techniques such as role-play to replicate highly varied stressors that elicit stuttering in members of this population. While useful, however, these role-play scenarios are not as effective as real-world situations. In this preliminary study we created a Mixed Reality (MR) speech experience to test whether this medium delivers the realism necessary to create heightened anxiety and consequent stuttering. Monitoring the stress response of the participant may provide a means for identifying everyday triggers that elicit stuttering. Specifically, our aim was to determine the efficacy of the MR environment by monitoring participants' physiological responses such as arousal and anxiety, as well as their amount of speech disruption. The goal was to study this novel methodology for designing realistic and effective clinical environments for use by clinicians.

Just as with the TeachMETM experience, we wished to enhance the believability of virtual character behaviors while staying within reasonable cost constraints. We approached this task by utilizing interactors to play the roles of persons involved in a clinically based speech situation. Noninvasive and wireless physiological data collection devices collecting electroencephalography (EEG), heart rate, and interbeat heart rate interval (IBI) were used to measure the participants' level of arousal and workload during an MR restaurant experience.
Participants in the pilot study were one adult male and one adult female participant, both of whom were enrolled for fluency treatment. Each participant experienced a MR restaurant scenario, interacting with restaurant personnel as in the real world. The participants were subjected to multiple speech situations: (1) ordering in a restaurant, (2) being asked to give full name, (3) talking to someone of the opposite gender, (4) answering a specific question, (5) being rushed, (6) being asked to repeat an answer, and (7) being misunderstood.

In addition, the waiter's demeanor was changed from supportive and patient to unsupportive and impatient. This change was accomplished by introducing a new waiter halfway through the scenario, who required the participant to repeat the order without a menu. Given the complexity involved in creating realistic virtual characters, interactors were used to determine which behaviors had to be modeled in a future version of the speech situation scenario.

In the scenario the restaurant environment is viewed through a video see-through Canon Coastar VH2002 lightweight head-mounted display (HMD) (Uchiyama et al., 2002). Figure 5 shows a view of the MR renderings of an actual restaurant. Real objects found in a restaurant, such as tables, are part of the MR experience.

Figure 6 illustrates our analysis technique for synchronizing the psychometric data with coded stuttering behaviors elicited from the speech situations and change of server presented during the experience. The stuttering behaviors can be assessed via video playback of the participant's performance. The observation code of the participant's stuttering behavior aligns these behaviors with the psychometric data for visual inspection of the data. Once time points for stuttering behavior are identified, further statistical analysis of the psychometric data can be done.

Results from the pilot study suggest that physiological sensing devices may be used in an MR environment and 

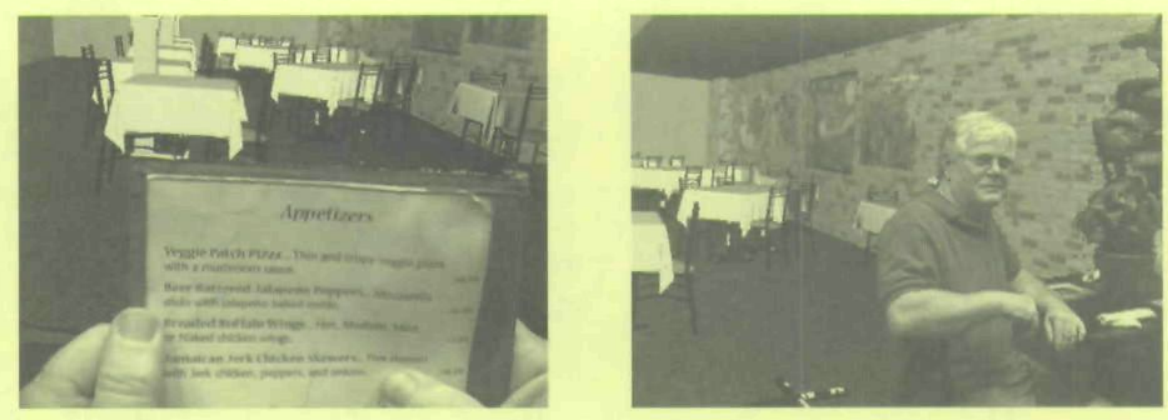

\section{FIGURE 5}

Images from MR rendering of a restaurant designed for exploring stressors in PWS. Left: a scene from HMD, with the subject reading a real menu.

Right: a scene from HMD, in which the subject is viewing the virtual restaurant augmented by real objects (another person, plants, table, napkin, utensils).

have the potential to qualify individual differences in stuttering behavior. Further, the approach provides a cost-effective methodology for creating realistic scenarios that may become part of the therapeutic environment. The use of neurosensing devices in the manner employed here has the potential to extend our capability of assessing the effectiveness of simulated learning environments for other applications across a range of learners' abilities and disabilities.

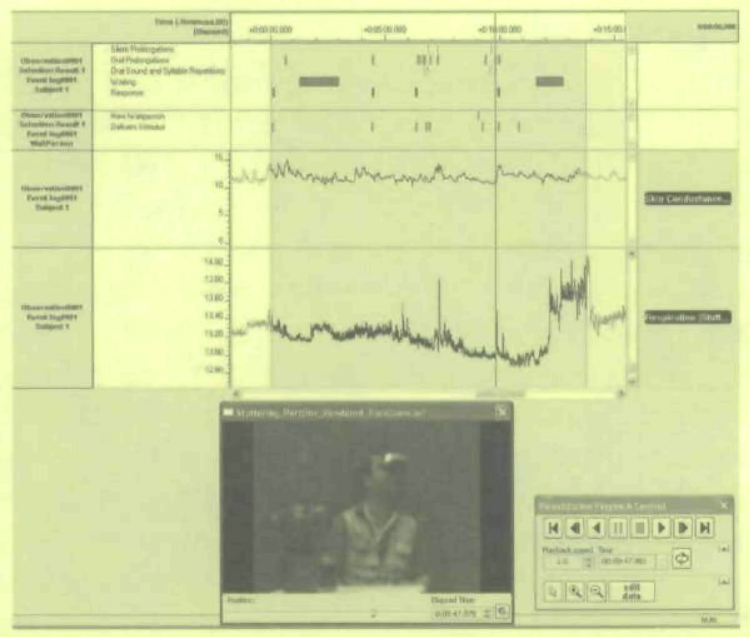

FIGURE 6

Observational coding strategy example with video playback of the participant's performance and synchronized psychometric data aligning delivery of interaction stimuli and participant's verbal response.

\section{The MR Supply Depot}

In a Phase I effort funded by the Air Force Office of Scientific Research, we designed an MR setting to simulate the experience of working in a busy supply warehouse. The user has the opportunity to work as a supply clerk tasked with stocking bins and taking care of order forms. During the simulation the user's primary objective is to fill each supply bin with the corresponding tool. To do so requires first scanning the bin with a bar code scanner and then scanning the appropriate tool, followed by placing it in the bin. Tool items can be found scattered in supply boxes. Increasing numbers and intensity of distractions are introduced during the scenario. Customer order forms are printed, shifting the user's priority to completing that order as the manger repeatedly asks over the intercom whether orders have been filled. Another task designed into the experience is the user's ringing of a bell that alerts the manager of a docking supply truck.

The physical work area is a $10^{\prime} \times 10^{\prime}$ space enclosed by blue curtain lining and blue wooden walls. A work counter is located at the front of the work area. Customer order forms will print from the printer located on this front counter. Also, any completed orders will be placed in the large bin on the far left side of the counter. The counter itself is painted blue to fit the design of the virtual supply warehouse (Figure 7). On the right side of the work area is a closet with three shelves storing the black supply bins. Eight shipping cartons are found on the left side of the work area, with four boxes stacked on the other four. The top level of boxes contains supplies that include cable ties, paint brushes, twine, screws, flat corner braces, and extension cords. One of the four audio speakers is stationed at each of the four corners in the $10^{\prime} \times 10^{\prime}$ space, providing a better sense of immersion. 


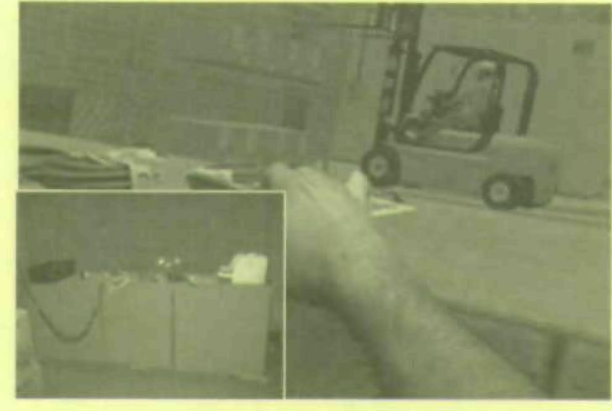

FIGURE 7

\section{Left: real counter with blue screen surround;} Right: environment viewed through HMD.

The virtual environment captures the lively essence of a busy supply warehouse. Electrical hums and fans operate as background noise while animated forklifts rush from destination to destination, receiving, loading, and storing. Users are able to hear the operation of the forklift as it stores boxes in higher shelves. Dock doors occasionally open, and the user can hear the warnings as the supply trucks back into the loading docks.

\section{Analysis of Warehouse Experience}

To determine the correlation between distracting events and user performance, we fitted each participant with the BAlert EEG, a patented wireless sensor that can acquire six channels of high-quality electroencephalographic (EEG) signals 30 feet from the computer data collection station. The mobility of this device allows for operation in workplace environments. Signal processing includes capabilities to identify and decontaminate the artifact during use. The validated measures of attention, workload, and distraction are recorded on a second-by-second basis and are available in report format for later review (Berka et al., 2004). In this study we used the EEG to measure the engagement, workload, and distraction levels of healthy participants while they performed work in the mixed reality warehouse depot.

In previous work the UCF team has shown that the EEG measures of engagement and workload can assist in determining the efficacy of a mixed reality-based rehabilitation environment within the feasibility stage (Fidopiastis et al., 2007). To obtain these classifications, we performed a 20 minute baseline task consisting of a three-choice vigilance task, eyes-open rest task, and an eyes-closed task. The results of these tests were used to fit an attention and distraction algorithm to obtain the proper classifications for each construct during data collection. The strength of this approach is that data then can be processed per individual or in aggregate.
The participants showed a mix of high and low engagement with frequent distraction. They also showed phases of high and low workload levels. Distraction was associated mostly with the audio stimuli for the printer. The changes in workload are not correlated with any specific aspect of the scenario. Further analysis of individual performance including task strategy may show distinct associations between tasks that demand more cognitive resources than others.

Overall, the results show that the EEG measures of Engagement and Workload are good indicators of how the task affected the healthy participants. These data can be used to obtain an understanding of cognitive aspects of the task that may pose challenges to head-injured patients. The EEG measures also show how distracters within the scenario affected performance from a cognitive processing perspective. This information is imperative to know not only for virtual rehabilitation therapy protocols but also for the field of rehabilitation in general.

The experiment just described shows how we can place both teachers and students in naturalistic contexts, where visual, aural, and task-based distractions can be introduced while the subjects' physical and neurological states are monitored. This would allow us, for instance, to determine triggers that set off teachers in training, enabling us to apply intervention before the situation arises in a classroom. Similar settings can be used to evaluate attention deficit in students, placing the student in an appropriate context but not subjecting him or her to observation by real classmates.

\section{Free-Choice Learning}

In 2004, MCL developed an experiment called Journey with Sea Creatures (SC), which we ran at the Orlando Science Center (OSC) in its Dino Digs exhibit. This exhibit was a cornerstone of the science center when it was first installed, and it showcased large, impressive prehistoric fossil displays. Yet, when visitors came into the hall, they left shortly thereafter. Even though the plaques had detailed information, most people did not bother to read them.

The center had few choices to solve the problem: It could be left as is, or the exhibit could be gutted and redone, or the empty space filled with a rented exhibit. Either of the latter choices would involve a lot of work and investment without much return. A fourth option was needed to avoid large capital expense and at the same time increase the educational and entertainment value that would attract more people, who would stay longer and come back. This is where MR came into play, but with the constraint that expensive and confining HMDs could not be used.

As you entered Dino Digs during the installation, you were surrounded by prehistoric fossils in an attack position ready to devour you. Prior to incorporating Mixed 
Reality, visitors had little to do besides reading the panels and playing in some sand. The challenge was to spark interest to motivate them to learn more and maybe even read the plaques. After entering the exhibit, parents or kids could peer through the MR Portal (Figure 8), seeing a live video feed of the museum augmented with synthetic content including a virtual docent. After an introduction, the venue was virtually flooded with water, as seen through the portal. Prehistoric marine reptile fossils grew muscle and skin and came to life, swimming around the exhibit.

Users had multiple views from which to interact with the environment. Through the portal, they had a stationary augmented reality view with water and dinosaurs overlying the exhibit and other guests. Occlusion models allowed for virtual content to flow around exhibit features, moving and disappearing behind and in between structures. On the user's control panel a trackball operated a virtual, unmanned underwater vehicle to explore the exhibit space for artifacts. A monitor in the podium displayed a virtual telepresence viewpoint of the underwater vehicle to guide the viewer through the exhibit to find artifacts.

Also on the monitor was a heads-up display with readings of health, cargo, research reference, and other data. A radar display identified the spots where critical artifacts could be found. This mixed reality enhancement encouraged further investigation of the real exhibit by enticing the visitor to participate in a journey of discovery that includes both real and virtual components.

The topic was exploring Florida during the Cretaceous Period when it was underwater-when prehistoric reptiles swam the earth. The flooding was a dramatic moment for the participants, and it also drove home the relevance that the events took place in their own community. During the onemonth field study a third-party evaluator observed the exhibit. She observed the duration of interaction and surveyed the propensity for repeat visits and patronage to similar exhibits. The results revealed that the younger guests extended their exhibit stay beyond 10 minutes and up to 30 minutes or until the parents pulled them away.

The scenario encouraged discussion by visitors of all ages. The most surprising observation was how much the imagination of the audience was able to extend the virtuality beyond the displays to areas that had no technology. During the experience some kids chose at points to pretend to swim through the hall instead of walking.

Over the course of field testing, evaluations revealed that more than $80 \%$ of the guests either agreed or strongly agreed that MR enhanced the entertainment experience, added educational value, enticed them to visit similar exhibits, and encouraged extended and repeat play. This provided a better experience for guests and also enhanced the potential economic performance of the exhibit. These types of MR environments could provide new opportunities for teachers in classrooms, new ways to provide multiple choices for students in the class or, most important, new ways to engage and stimulate the brains of learners that more traditional approaches may not reach. Much like our more traditional example of handwriting or reading, providing new, perhaps yet to be discovered, ways to master learning that did not exist in the past is perhaps further leveling the playing field for unique ways for students with disabilities to master content.

Water's Journey through the Everglades, an NSF-funded project, is building on the Sea Creatures experiment and developing learning enhancements for the Ft. Lauderdale Museum of Discovery and Science (MODS) new EcoDiscovery Wing expansion project. Guests will explore the complexities and diversity of life that make up the creation, destruction, and restoration of the Florida Everglades and embark on an adventure spanning millions of years. Water's Journey will develop learning-enhancement scenarios for the upcoming expansion at MODS. The unique learning experiences will integrate scientific data from national research institutions and apply state-of-the-art scientific virtualization tools to create customized learning experiences
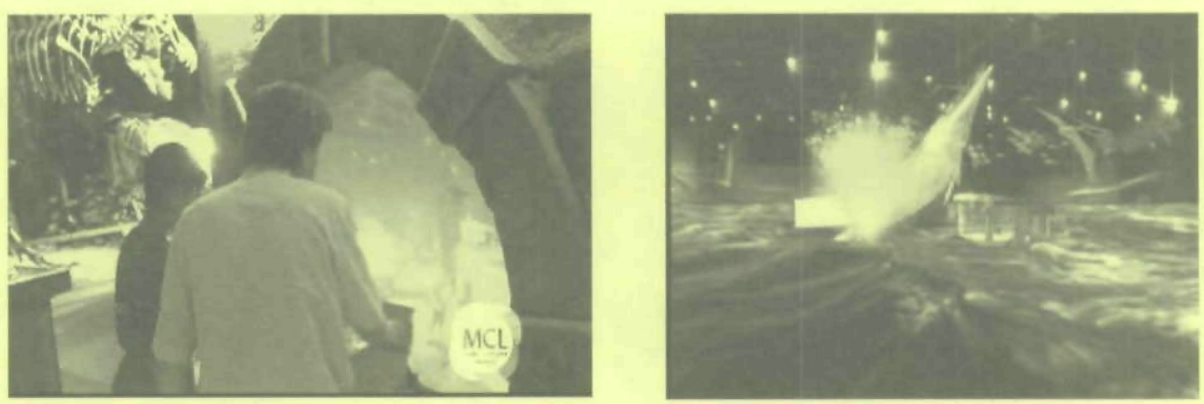

FIGURE 8

A Mixed Reality kiosk with content example for Journey With Sea Creatures field-testing at the Orlando Science Center's Dino Digs exhibit. 
that will allow visitors to explore the scale and timing of environmental change using the concepts of Universal Design for Learning to ensure access for all.

This project creates a bridge from scientific research to informal science education by transferring the data sets collected in the field and the virtualization tools used by scientists into the hands of museum learners. The approach employs and advances the simulation technology that already has captured the attention of the adolescent audience. Whether through large display portals, virtual windows, telepresence cameras, or environmental simulators, learners will discover highly interactive and playful virtual content that engages cross-generational groups into playful exploration of Water's Journey.

The overall goals of the learning enhancements are to allow the learners to manipulate time, scale, and place to add layers of exploratory investigation into the rich physical exhibit experience and to capture data from the learners that will permit comparison between attitudes, knowledge, and priorities within that community of learners, increasing their understanding of sustainability and consequences. The project deliverables have been selected to build on prior research that demonstrates how various learning environments have their unique roles in successful learning, and research that explores how to capture the imagination of the visitors with technology that enhances a physical exhibit hall.

The goal of Water's Journey is to re-engage the adolescent audience with science centers by providing a tool that can deliver a continuous flow of compelling interactive content, supporting a lifetime of inquiry and experimentation. The dynamic nature of the technology infrastructure will provide a national model for customization of scientific data to address individual community issues (water-related or not), scalable for use in any size of science institution that educates the public in informal settings, with a web portal that allows models to be created at home that link back to competitions at the museum for multiple age groups. The web portal will allow learners to access their collected data from the home or classroom environment. The result will expand the depth and options of the exhibit experience.

\section{WHAT'S NEXT?}

Determining what's next is a timeless question-but one without a solid answer. One thing that has to come next is the creation of schools that are flexible, dynamic, engaging, and that embrace a new generation of learners whether they are with or without disabilities. The digital divide between cultures is closing, but the divide between what students have in their home and society compared to school may be the new digital divide. One way to close this gap is to develop a different teaching force that is prepared and embraces these new tools. Another way is to provide opportunities for students with disabilities not only to take advantage of but also to prosper by meeting their needs through new technological tools. Then, finally, just as students with disabilities must be included to the maximum extent appropriate into the general education setting, they must be included into virtual environments and online worlds, not because they are essential tools for life but because without this type of involvement, the gap between abilities and disabilities will grow in school and in society as well.

Independent of educational needs, these technologies will continue to emerge, but what we hope to have demonstrated is that, as these tools have been used to solve numerous problems for people with and without disabilities, something else is happening. No longer do we find in our work that educators simply talk and reflect with other educators but, when futuristic technologies are at the core of a vision, a spectrum of professionals becomes engaged in solving a common set of core values of concern in our society-that of education. Producing better teachers means that more students can enter into advanced fields such as engineering, computer science, and teaching. Simultaneously, these fields are different because of the transfer of knowledge. For people with disabilities and their families, technological advances may not be the solution, but they do provide options for a different tomorrow in schools, classrooms, and society for a range of differently abled learners.

\section{ACKNOWLEDGMENTS}

The authors wish to acknowledge the support provided by the U.S. Department of Education through its SBIR program and Chris Stapleton through Simiosys, and the dedicated contributions of Dan Mapes, our chief software developer, and Jeff Wirth, the mentor of our wonderful Interactors. We also would like to acknowledge the ongoing partnership with Dr. Martin Haberman and the Haberman Foundation staff.

\section{REFERENCES}

Allen, M. B. (2005). Eight questions on teacher recruitment: What does the research say? Denver: Education Commission of the States. Retrieved November 14, 2005, from http://www.ecs.org/html/edu cationissues/teachingquality/trreport/report/introduction.asp

Berka, C, Levendowski, D.J., Cvetinovic, M, Petrovic, M.M., Davis, G.F., Lumicao, M.N., Popovic, M.V., Zivkovic, V.T., Olmstead, R.E., \& Westbrook, P. (2004). Real-time analysis of EEG indices of alertness, cognition and memory acquired with a wireless EEG headset. [Special Issue] International Journal of Human-Computer Interaction on Augmented Cognition, 17(2), 151-170.

Blair, J. (2003, April 30) Community colleges offering 4-year teaching programs. Education Week, 22(33) pp. 1, 22-23. 
Boe, E. E., Bobbitt, S. A., \& Cook, L. H. (1997). Whither didst thou go? Retention, reassignment, migration, and attrition of special and education teachers from a national perspective. Journal of Special Education, 30(4), 371-389.

Boe, E. E., Bobbitt, S. A., Cook, L. H., Whitener, S. D., \& Weber, A. L. (1997). Why didst thou go? Predictors of retention, transfer, and attrition of special and general education teachers from a national perspective. Journal of Special Education, 30, 390-411

Carnegie Council on Adolescent Development. (1995). Great transitions: Preparing adolescents for a new century. New York: Carnegie Corporation.

Cobb, N. J. (1994). Adolescence: Continuity, change, and diversity. Mountain View, CA: Mayfield Publishing.

Colburn, A. 2006. What teacher educators need to know about inquirybased instruction. Paper presented at annual meeting of Association for the Education of Teachers in Science, Akron, OH. Retrieved April 2007 from www.csulb.edu/acolburn/AETS.htm

DaCosta, B. 2007. Virtual character theoretical framework. Unpublished paper, University of Central Florida, Media Convergence Laboratory.

Darling-Hammond, L. (2003). Keeping good teachers, Educational Leadership, 60(8), 6-13.
Darling-Hammond, L., \& Green, J. (1990). Teacher quality and equality. In J. I. Goodlad \& P. Keating (Eds.), Access to knowledge: An agenda for our nation's schools. New York: College Entrance Examination Board.

Darling-Hammond, L., \& Sykes, G. (2003). Wanted: A national manpower policy for education. Denver: Education Commission of the States.

Dieker, L., Hynes, M., Stapleton, C. B., \& Hughes, C. E. (2007) Virtual Classrooms: STAR Simulator, New Learning Technologies 2007. (Orlando, FL, February 2007).

Dreikurs, R. (1958). Children: The challenge. New York: Norton.

Dreikurs, R. (1968). Maintaining sanity in the classroom. New York: Harper and Row.

Dreikurs, R., \& Cassel, P. (1965). Discipline without tears. New York: Harper and Row.

Dreikurs, R. and Cassel, P (1972). Discipline without tears (2nd ed., pp. 1-84.). New York: Plume.

Dreikurs, R., \& Grey, L (1968). The new approach to discipline: Logical Consequences (pp. 1-82). New York: Plume.

Dziuban, C.D., Moskal, P.D., \& Dziuban, E.K. (Fall, 2000), Reactive behavior patterns go online. Journal of Staff, Program, \& Organizational Development, 17(3), 171-182.

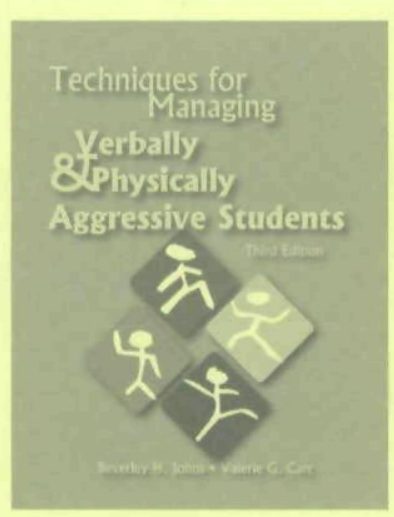

\section{Techniques for Managing Verbally \& Physically Aggressive Students Third Edition BEVERLEY H. JOHNS AND VALERIE G. CARR}

The latest edition of this classic book incorporates new strategies for handling violence and inappropriate behavior in our schools, including the implications of new technologies like cell phones, social networking, and cyberbullying. The authors provide how-to information and step-by-step methods for working with disciplinary problems and aggression within the school setting. They focus specifically on techniques for breaking up fights, intervening in bullying, and working with students who talk back and refuse to do their work.

These classroom management techniques provide tangible results. Strategies for school-wide behavior management and community and parent involvement provide an integrated and comprehensive approach to addressing violence in our schools.

\section{LOVE PUBLISHING COMPANY}

9101 East Kenyon Avenue, Suite 2200

Denver, Colorado 80237

303-221-7333 • 303-221-7444 (fax)

\section{CONTENTS}

I. Facing the Challenge

2. The Classroom Climate

3. Ineffective Classroom Management Techniques

4. Successful Behavior Management

5. Behavioral Intervention Plans

6. Understanding Aggression

7. Dealing With Aggressive Behavior

8. Verbally Dealing With Aggression

9. Use of Time-Out

10. Bully-Proofing Your Classroom

II. Dealing With Physical Aggression

12. Breaking Up Fights

13. Police Intervention and Community Agency Involvement

14. Working Effectively With Parents

15. Administrative Issues

Appendixes 
Erikson, E. H. (1968). Identity: Youth and crisis. New York: W. W. Norton.

Evans, R. L. (1973). Jean Piaget: The man and his ideas. New York: E.P. Dutton \& Co.

Fidopiastis, C. M., Hughes, C. E., Smith, E. M. \& Nicholson, D. M. (2007). Assessing virtual rehabilitation with biophysical metrics, Virtual Rehabilitation 2007. (Venice, Italy, September 27-29, Poster)

Fidopiastis, C. M., Stapleton, C. B., Whiteside, J. D., Hughes, C. E., Fiore, S. M., Martin, G. A., Rolland J. P., \& Smith, E. M. (2006). Human experience modeler: Context driven cognitive retraining to facilitate transfer of training, CyberPsychology and Behavior 9(2), 183-187.

Flanagan, A. \& Grissmer, D. (2002). The role of federal resources in closing the achievement gap. In J. E. Chubb \& T. Loveless (Eds.), Bridging the achievement gap. Washington, DC: Brookings Institute.

Grissmer, D.W., \& Kirby, S.N. (1997). Teacher turnover and teacher quality. Teachers College Record, 9(1), 45-56.

Haberman, M. (2006). Star teachers of children of poverty. Houston: Haberman Education Foundation.

Hamburg, B. (1974). Early adolescence: A specific and stressful stage of the life cycle. In G. Coehol, D. A. Hamburg, \& J. E. Adams (Eds.), Coping and adaptation (pp. 101-125). New York: Basic Books.

Hughes, C. E., Stapleton, C. B., Hughes, D. E. \& Smith E. (2005). Mixed reality in education, entertainment and training: An interdisciplinary approach. IEEE Computer Graphics and Applications, 26(6), 24-30.

Ingersoll, R.M. (2001). Teacher turnover and teacher shortages: An organizational analysis. American Educational Research Journal, 38(3): 499-534.

Kaiser Family Foundation (2004). Parents, media and public policy. Menlo Park, CA: Author.

Leavell, A.G., Cowart, M., \& Wilhelm, R.W. (1999). Strategies for preparing culturally responsive teachers. Equity and Excellence in Education, 32, 64-71

Long, W.A., Jr. (1985, March). The practitioner and adolescent medicine. Seminars in Adolescent Medicine, 1(1).

Long, W.A.. Jr. (1989) Personality and learning: 1988 John Wilson Memorial Address. Focus on Learning, 11(4).

Murnane, R., Singer, J., Willett, J., Kemple, J., \& Olsen, R. (Eds.). (1991). Who will teach? Policies that matter. Cambridge, MA: Harvard University Press.

National Commission on Teaching and America's Future. (2003). No dream denied: A pledge to America's children, Summary Report. Retrieved from http://www.nctaf.org/documents/no-dream-denied _summary_report.pdf
Portner, H. (2005). The success of new teachers. American School Board Journal, pp. 30-33.

Pruitt, D. B. (Ed.) (2000). Emotional, behavioral and cognitive development from early adolescence through the teen years. Washington, D.C.: The American Academy of Child and Adolescent Psychiatry.

Riley, R. (1998) Our teachers should be excellent and they should look like America. Education and Urban Society, 3I(1), 18-29.

Rose, D. H., \& Meyer, A. (2000). Universal design for learning. Journal of Special Education Technology 15(1): 67-70.

Rose, D. H., Meyer, A., \& Hitchcock, C. (2005). The universally designed classroom: Accessible curriculum and digital technologies. Cambridge, MA: Harvard Education Press.

Russell, M. (2003). Examining teacher technology use implications for preservice and inservice teacher preparation. Journal of Teacher Education, 54(4), 297-310.

Simmons, R. G., \& Blyth, D. A. (1987). Moving into adolescence: The impact of pubertal change and school context. New York: Aldine DeGruyter.

Stapleton, C. B. \& Hughes, C. E. (2005). Mixed reality and experiential movie trailers: Combining emotions and immersion to innovate entertainment marketing. Proceedings of 2005 International Conference on Human-Computer Interface Advances in Modeling and Simulation (SIMCHI'05), New Orleans, January 23-27, pp. 40-48.

Stapleton, C. B. \& Hughes, C. E. (2006). Believing is seeing. IEEE Computer Graphics and Applications, 27(1), 88-93.

Uchiyama, S., Takemoto, K., Satoh, K., Yamamoto, H. \& Tamura, H. (2002). MR platform: A basic body on which mixed reality applications are built. IEEE and ACM International Symposium on Mixed and Augmented Reality (ISMAR 2002), Sept. 30-Oct. 1, Darmstadt, Germany.

U.S. Department of Education, National Center for Education Statistics. (2005). The condition of education 2005 (Rep. No. NCES 2005-094). Washington, DC: U.S. Department of Education, National Center for Education Statistics.

Whitworth, J. (2000). In capitalizing on leadership in rural special education: Making a difference for children and families. Paper presented at meeting, Preparing, recruiting and retaining special education personnel in rural areas, Alexandria, VA.

Wolfgang, C. H. (2001). Solving discipline and classroom management problems: Methods and models for today's teachers. New York: John Wiley and Sons.

Zeichner, K. (2003). The adequacies and inadequacies of three current strategies to recruit, prepare, and retain the best teachers for all students. Teachers College Record, 105, 490-519. 
Copyright of Focus on Exceptional Children is the property of Love Publishing Company and its content may not be copied or emailed to multiple sites or posted to a listserv without the copyright holder's express written permission. However, users may print, download, or email articles for individual use. 